Article

\title{
microRNA Profile Associated with Positive Lymph Node Metastasis in Early-Stage Cervical Cancer
}

\author{
Salim Abraham Barquet-Muñoz ${ }^{1,+}$ (D) Abraham Pedroza-Torres ${ }^{2,+}$ (D) Carlos Perez-Plasencia ${ }^{3}$ (D), \\ Sarita Montaño ${ }^{4}$ (D), Lenny Gallardo-Alvarado ${ }^{5}$, Delia Pérez-Montiel ${ }^{6}$, Luis Alonso Herrera-Montalvo ${ }^{7}$ (D) \\ and David Cantú-de León ${ }^{8, *(D)}$
}

check for updates

Citation: Barquet-Muñoz, S.A.; Pedroza-Torres, A.; Perez-Plasencia, C.; Montaño, S.; Gallardo-Alvarado, L.; Pérez-Montiel, D.; Herrera-Montalvo, L.A.; Cantú-de León, D. microRNA Profile Associated with Positive Lymph Node Metastasis in Early-Stage Cervical Cancer. Curr. Oncol. 2022, 29, 243-254. https:// doi.org/10.3390/curroncol29010023

Received: 26 August 2021 Accepted: 29 November 2021 Published: 8 January 2022

Publisher's Note: MDPI stays neutral with regard to jurisdictional claims in published maps and institutional affiliations.

Copyright: (C) 2022 by the authors. Licensee MDPI, Basel, Switzerland. This article is an open access article distributed under the terms and conditions of the Creative Commons Attribution (CC BY) license (https:// creativecommons.org/licenses/by/ $4.0 /)$.
1 Programa de Maestría y Doctorado en Ciencias Médicas, Odontológicas y de la Salud, UNAM, Mexico City 14080, Mexico; sbarquetm@incan.edu.mx

2 Cátedra CONACYT-Basic Research Division, Instituto Nacional de Cancerología, Mexico City 14080, Mexico; apedrozato@conacyt.mx

3 Genomics Laboratory, Basic Research Division, Instituto Nacional de Cancerología, Mexico City 14080, Mexico; carlos.pplas@unam.mx

4 Bioinformatics Laboratory, Biological Chemistry Sciences Department, Universidad Autónoma de Sinaloa (FCQB-UAS), Culiacan 80040, Mexico; mmontano@uas.edu.mx

5 Clinical Research Subdivision, Basic Research, Instituto Nacional de Cancerología, Mexico City 14080, Mexico; lgallardoa@incan.edu.mx

6 Department of Pathology, Instituto Nacional de Cancerología, Mexico City 14080, Mexico; mperezm@incan.edu.mx

7 Cancer Biomedical Research Unit, Instituto Nacional de Cancerología and Instituto Nacional de Medicina Genómica, Mexico City 14080, Mexico; herreram@biomedicas.unam.mx

8 Division of Research, Instituto Nacional de Cancerología, Av. San Fernando \#22, Mexico City 14080, Mexico

* Correspondence: dcantul@incan.edu.mx; Tel.: +52-55-5628-0400 (ext. 21016)

+ These authors contributed equally to this work.

\begin{abstract}
Lymph node metastasis (LNM) is an important prognostic factor in cervical cancer (CC). In early stages, the risk of LNM is approximately 3.7 to $21.7 \%$, and the 5 -year overall survival decreases from $80 \%$ to $53 \%$ when metastatic disease is identified in the lymph nodes. Few reports have analyzed the relationship between miRNA expression and the presence of LNM. The aim of this study was to identify a subset of miRNAs related to LNM in early-stage CC patients. Formalin-fixed paraffin-embedded tissue blocks were collected from patients with early-stage CC treated by radical hysterectomy with lymphadenectomy. We analyzed samples from two groups of patients-one group with LNM and the other without LNM. Global miRNA expression was identified by microarray analysis, and cluster analysis was used to determine a subset of miRNAs associated with LNM. Microarray expression profiling identified a subset of 36 differentially expressed miRNAs in the two groups (fold change (FC) $\geq 1.5$ and $p<0.01$ ). We validated the expression of seven miRNAs; miR-487b, miR-29b-2-5p, and miR-195 were underexpressed, and miR-92b-5p, miR-483-5p, miR-4534, and miR-548ac were overexpressed according to the microarray experiments. This signature exhibited prognostic value for identifying early-stage CC patients with LNM. These findings may help detect LNM that cannot be observed in imaging studies.
\end{abstract}

Keywords: miRNAs; cervical carcinoma; lymph node metastasis

\section{Introduction}

Cervical carcinoma (CC) is one of the most common cancers in women from lowincome and middle-income countries; in Mexico, CC is the second most common tumor and has a high mortality rate [1]. The most important factors affecting survival of patients with early-stage CC (International Federation of Gynecology and Obstetrics (FIGO) stage IA-IB1) are the clinical stage, tumor size, depth of tumor invasion into the stroma, lymphovascular space invasion (LVSI), and presence of lymph node metastasis (LNM). The 
primary treatment is radical hysterectomy $(\mathrm{RH})$ with bilateral pelvic lymphadenectomy (BPL) [2].

In early stages, the risk of LNM is approximately 3.7 to $21.7 \%$, and the 5 -year overall survival (OS) decreases from $80 \%$ to $53 \%$ when metastatic disease is identified in the lymph nodes (LNM+) [3-6]. Therefore, the FIGO updated their staging system in 2018 by incorporating nodal status into stage III disease. The standard technique to identify positive lymph nodes is based on advanced imaging methods such magnetic resonance imaging (MRI), computed tomography (CT), or positron emission tomography-CT (PET)-CT. The accuracy of each of these modalities ranges from 70 to $85 \%$, and the lymph nodes must reach a minimum size to be identified by imaging studies. Microscopic disease cannot be detected by noninvasive methods [7-10].

MicroRNAs (miRNAs) are single-stranded RNAs comprising approximately 21-23 nucleotides and are essential in a wide variety of physiological and pathological processes, including development, differentiation, metabolism, immunity, cell cycling, proliferation, apoptosis, cell identity, and stem cell maintenance. They regulate gene expression by inhibiting posttranscriptional events and, in some cases, they induce the degradation of their target messenger RNA [11-13]. In cancer, miRNAs can function as oncogenes and/or tumor suppressor genes depending on the function of their target genes. Abnormal expression of miRNAs is linked to several features of cancer biology, including proliferation, differentiation, apoptosis, migration, invasion, and metastatic angiogenesis [14-17].

Numerous studies have demonstrated the role of miRNAs in the development and prognosis of CC [18-21]. Some of the miRNAs identified in CC include miR-23b, miR-143, let-7b, let-7c, miR-196b, miR-9, miR-127, miR-133a, miR-133b, and miR-145 [13,22]. Moreover, some studies have shown that miRNAs act as prognostic markers in CC [13,23-25]. As previously mentioned, MRI, CT, and PET-CT scans cannot identify all patients with early-stage CC and LNM, and the use of miRNAs as molecular markers for the LNM+ status in the early stages of CC remains poorly studied. The aim of this study was to identify a subset of miRNAs related to positive LNM in early-stage CC patients.

\section{Materials and Methods}

\subsection{Patients and Tumor Samples}

Formalin-fixed paraffin-embedded (FFPE) tissue blocks from early-stage CC patients treated with RH and BPL who were diagnosed between January 2006 and December 2013 at the Instituto Nacional de Cancerología (Mexico City) were reviewed. The exclusion criteria were patients with 2 primary tumors, primary treatments other than $\mathrm{RH}$, or poor quality of the tissue in the FFPE blocks. The FFPE blocks were stained with hematoxylin and eosin (H\&E) to identify tumor regions and verify a minimum presence of $80 \%$ of tumor cells. Subsequently, total RNA was extracted from 5 sections $(10 \mu \mathrm{m})$ from the selected FFPE blocks. For the analysis, LNM+ patients were paired with a similar number of patients without LNM (LNM-) matched by age, tumor size, and the presence of LVSI.

\subsection{RNA Extraction}

Total RNA was extracted using an miRNeasy FFPE Kit (QIAGEN) according to the manufacturer's instructions. First, 5 sections $(10 \mu \mathrm{m})$ were deparaffinized using $320 \mu \mathrm{L}$ of deparaffinization solution and incubated at $56^{\circ} \mathrm{C}$ for $3 \mathrm{~min}$. Subsequently, the samples were treated with $10 \mu \mathrm{L}$ of Proteinase $\mathrm{K}$ and incubated at $56^{\circ} \mathrm{C}$ for $15 \mathrm{~min}$ and at $80^{\circ} \mathrm{C}$ for $15 \mathrm{~min}$. Then, the samples were treated with $500 \mu \mathrm{L}$ of RBC buffer to adjust the binding conditions. Next, $500 \mu \mathrm{L}$ of RPE buffer was added to the samples, and the mixture was transferred to a RNeasy MinElute spin column. Finally, total RNA was eluted in $50 \mu \mathrm{L}$ of RNase-free water.

To verify the usefulness of the samples, RNU6B was amplified by RT-qPCR using TaqMan miRNA probes and the TaqMan MicroRNA Reverse Transcription Kit (Applied Biosystems, Waltham, MA, USA) according to the manufacturer's specifications. Samples 
for which RNU6B amplification was possible and that showed an adequate amount of total RNA ( $>50 \mathrm{ng} / \mu \mathrm{L}$ ) were used to identify their global miRNA expression profile.

\subsection{Global miRNA Expression Profiles}

Global miRNA profiles were identified using a GeneChip miRNA 3.0 Array (Affymetrix, Cat. 902018) following the manufacturer's instructions. The GeneChip miRNA 3.0 Array contains 19,724 probe sets and can quantify 1733 human mature miRNAs (miRBase v17). Initially, $500 \mathrm{ng}$ of total RNA was labeled using a FlashTag Biotin RNA Labeling Kit (Affymetrix, Santa Clara, CA, USA). Then, a poly(A) tailing reaction was performed at $37^{\circ} \mathrm{C}$ for $15 \mathrm{~min}$ (1X reaction buffer, $750 \mu \mathrm{L}$ of $\mathrm{MgCl}_{2}(25 \mathrm{mM}), 500 \mu \mathrm{L}$ of adenosine triphosphate (ATP), and $500 \mu \mathrm{L}$ of propyl aminopeptidase (PAP) enzyme). FlashTag ligation was immediately conducted at room temperature for $30 \mathrm{~min}$ ( $2 \mathrm{~mL}$ of $5 X$ FlashTag Ligation Mix Biotin and $1 \mathrm{~mL}$ of T4 DNA ligase), and $1.2 \mathrm{~mL}$ of stop solution was added to stop the reaction. Finally, the microarray was hybridized and washed using an Affymetrix Fluidics Station 450 and scanned with the Affymetrix GeneChip Scanner 3000. After processing the images, the raw data were obtained. Then, background correction and normalization were performed by the quantiles method using the robust multiarray average (RMA) tool in the affy package in $\mathrm{R}(3.5 .1 \mathrm{v})$. To obtain the miRNA profile, the processed samples were divided into 2 groups, LNM+ samples and LNM- samples, using the Limma package (Linear Models for Microarray Data) in R (3.5.1 v). Differentially expressed miRNAs were identified using a cutoff value of $p<0.01$ and a fold change (FC) of 1.5. Finally, we constructed a heatmap with the differentially expressed miRNAs in the two groups of samples using the heatmap.2 function in R (3.5.1 v) and the nonsquared Euclidean distances method (Ward.D2) [26].

\subsection{Validation of the miRNA Profiles by RT-qPCR}

Ten miRNAs were selected to validate the data obtained through the microarray experiments in the same cohort of patients ( $n=20,10$ LNM+ samples and 10 LNMsamples) using miRNA-specific stem-loop primers and a TaqMan MicroRNA Reverse Transcription Kit. First, cDNA was synthesized using specific primers for each miRNA according to the manufacturer's specifications. Subsequently, the quantification reaction consisted of $10 \mu \mathrm{L}$ of $2 X$ TaqMan Fast Universal PCR Master Mix No AmpErase UNG, $1 \mu \mathrm{L}$ of $0.2 \mu \mathrm{M}$ TaqMan probe, and $1.33 \mu \mathrm{L}$ of cDNA. All reactions were performed in triplicate using a GeneAmp PCR system 9700 thermal cycler (Applied Biosystems) with the following thermocycling program: $16^{\circ} \mathrm{C}$ for $30 \mathrm{~min}, 42^{\circ} \mathrm{C}$ for $30 \mathrm{~min}$, and $85^{\circ} \mathrm{C}$ for $5 \mathrm{~min}$. RNU6B (assay ID: 001093) was used as an endogenous control to normalize the miRNA expression level. The mean $\mathrm{Ct}$ values in each qPCR were used to calculate miRNA relative expression. Finally, $2^{-\Delta \Delta \mathrm{Ct}}$ values were plotted [27].

\subsection{Prediction of miRNA Target Genes and Pathways}

To identify which genes and signaling pathways were regulated by the validated miRNA signature associated with LNM+ samples, we used the miRWalk 3.0 and DAVID 6.8 bioinformatics tools $[28,29]$. miRWalk 3.0 is a bioinformatics tool that allows the prediction of target genes through the miRNA-target gene interaction using the TarPmiR algorithm [30]. This approach allowed us to predict interactions between $5^{\prime}$-untranslated region (UTR), coding sequence (CDS), and $3^{\prime}$-UTR and the seed region of the miRNA candidate. In addition, miRWalk 3.0 uses the datasets of 2 prediction platforms (TargetScan and $\mathrm{miRDB}$ ) and the experimentally validated interaction information from miRTarBase. First, we selected miRNAs with expression validated by RT-qPCR and those that showed clinical significance to search for their target genes using the miRWalk 3.0 tool. Then, with the list of genes obtained, we performed Gene Ontology (GO) enrichment and Kyoto Encyclopedia of Genes and Genomes (KEGG) analyses to determine the functions of associated genes and pathways [31,32]. Finally, the interaction network between target genes and selected miRNAs was visualized with Cytoscape and CyTargetLinker bioinformatic tools [33,34]. 


\subsection{Statistical Analysis}

Quantitative data are expressed as the mean \pm standard deviation (SD). miRNA expression levels were compared between the 2 groups by an unpaired $t$ test. The chisquare test or Fisher's exact test was performed to assess the relationships between miRNA expression and clinical features. To determine the clinical correlation between the LNM+ status and the miRNA profile, logistic regression was performed between the expression values of miRNAs and lymph node status to calculate the odds ratio (OR). A p value less than 0.05 was considered statistically significant. Statistical analyses were performed using SPSS, version 23 (IBM Corp., Armonk, NY, USA). This study was approved by the local institutional review boards, with approval reference (INCAN/CI/248/15).

\section{Results}

\subsection{Patients and Samples}

A total of 25 samples were selected. Twelve samples were selected from LNM+ patients, and 13 samples were selected from LNM- patients. The clinical and histopathological characteristics are summarized in Table 1. A significant difference was found for the type of adjuvant treatment $(p=0.02)$ and depth of invasion $(p=0.04)$.

\section{2. miRNA Profile Associated with LNM+ Patients}

Microarray expression profiling identified a subset of 36 differentially expressed miRNAs between the 2 groups ( $F C \geq 1.5$ and $p<0.01$ ). A heatmap of the differentially expressed miRNAs showed that the samples were grouped with respect to lymph node status (Figure 1 and Supplementary File S1). Among the identified miRNAs, 17 were overexpressed, and 19 were underexpressed. Among the main dysregulated miRNAs, miR-487b ( FC $=-3.2, p=0.0003), \operatorname{miR}-194(\mathrm{FC}=-2.8, p=0.006), \operatorname{miR}-34 \mathrm{c}-5 \mathrm{p}(\mathrm{FC}=-2.46$, $p=0.007)$, miR-29b-2-5p (FC $=-2.3, p=0.007)$, and miR-195 (FC $=-2.07, p=0.001)$ were underexpressed, while miR-548ac ( $\mathrm{FC}=2.74, p=0.0003)$, miR-4534 $(\mathrm{FC}=2.47, p=0.001$, miR-483-5p ( $\mathrm{FC}=2.21, p=0.002), \operatorname{miR}-564(\mathrm{FC}=2.01, p=0.006)$, and miR-92b-5p $(\mathrm{FC}=1.82$, $p=0.005)$ were overexpressed. This molecular signature correctly classified $91.6 \%(11 / 12)$ of the LNM+ samples and $92.3 \%(12 / 13)$ of the LNM- samples.

\subsection{Validation of miRNAs by RT-qPCR}

To validate the data obtained through the microarray experiments, we selected 10 miRNAs based on their expression levels and $p$ values. We were able to validate the expression of 7 of the 10 selected miRNAs by RT-qPCR experiments (Figure 2); miR-487b, miR-29b-2-5p, and miR-195 were underexpressed, and miR-92b-5p, miR-483-5p, miR-4534, and miR-548ac were overexpressed according to the microarray experiments. The remaining three miRNAs showed positive correlations in the microarray experiments but did not show statistically significant differences (miR-194, miR-34c-5p, and miR-564).

Table 1. Clinical and histopathological characteristics of the patients with cervical carcinoma analyzed in this study.

\begin{tabular}{|c|c|c|c|}
\hline N (\%) & $\begin{array}{l}\text { With Lymph Node Involvement } \\
12(48)\end{array}$ & $\begin{array}{l}\text { Without Lymph Node Involvement } \\
\qquad 13(52)\end{array}$ & $p$ \\
\hline Age + & $54.92 \pm 8.89$ & $54.85 \pm 10.80$ & 0.98 \\
\hline \multicolumn{4}{|c|}{ Clinical Stage ^ } \\
\hline Ia2 & $0(0.0)$ & $1(7.7)$ & \\
\hline $\mathrm{Ib} 1$ & $12(100.0)$ & $10(76.9)$ & \\
\hline IIa1 & $0(0.0)$ & $2(15.4)$ & \\
\hline $\mathrm{BMI}+$ & $28.82 \pm 2.69$ & $30.36 \pm 4.23$ & 0.34 \\
\hline
\end{tabular}


Table 1. Cont.

\begin{tabular}{|c|c|c|c|}
\hline $\mathbf{N}(\%)$ & $\begin{array}{l}\text { With Lymph Node Involvement } \\
12(48)\end{array}$ & $\begin{array}{l}\text { Without Lymph Node Involvement } \\
\qquad 13(52)\end{array}$ & $p$ \\
\hline $\begin{array}{c}\mathrm{BMI}^{\wedge} \\
\leq 25 \\
25.1-30 \\
>30\end{array}$ & $\begin{array}{l}3(25.00) \\
4(33.33) \\
5(41.67)\end{array}$ & $\begin{array}{l}3(23.08) \\
2(15.38) \\
8(61.54)\end{array}$ & 0.67 \\
\hline $\begin{array}{c}\text { Type of adjuvant treatment } \\
\text { None } \\
\text { EBR or BT } \\
\text { CT/EBR+BT }\end{array}$ & $\begin{array}{l}0(0.00) \\
4(33.33) \\
8(66.67)\end{array}$ & $\begin{array}{l}4(30.77) \\
7(53.84) \\
2(15.38)\end{array}$ & 0.02 \\
\hline $\begin{array}{c}\text { Type of recurrence } \\
\text { None } \\
\text { Local } \\
\text { Regional } \\
\text { Distant }\end{array}$ & $\begin{array}{c}10(83.33) \\
1(8.33) \\
0(0.0) \\
1(8.33)\end{array}$ & $\begin{array}{c}13(100) \\
0(0.0) \\
0(0.0) \\
0(0.0)\end{array}$ & 0.22 \\
\hline $\begin{array}{c}\text { Histology^ } \\
\text { SCC } \\
\text { Adenocarcinoma } \\
\text { ASCC }\end{array}$ & $\begin{array}{l}8(66.67) \\
3(25.00) \\
1(8.33)\end{array}$ & $\begin{array}{c}10(76.92) \\
1(7.69) \\
2(15.38)\end{array}$ & 0.57 \\
\hline $\begin{array}{c}\text { Grade } \\
1 \\
2 \\
3\end{array}$ & $\begin{array}{c}0(0.0) \\
7(58.33) \\
5(41.67)\end{array}$ & $\begin{array}{l}1(7.69) \\
7(53.85) \\
5(38.46)\end{array}$ & 0.90 \\
\hline LVSI^ $^{\wedge}$ & $11(91.67)$ & $10(76.92)$ & 0.33 \\
\hline Invasion depth in $\mathrm{mm}^{*}$ & $15(10.5-17)$ & $10(7-11)$ & 0.04 \\
\hline $\begin{array}{c}\text { Thirds } \\
1 / 3 \\
2 / 3 \\
3 / 3\end{array}$ & $\begin{array}{l}1(8.33) \\
2(16.67) \\
9(75.00)\end{array}$ & $\begin{array}{l}3(23.08) \\
2(15.38) \\
8(61.54)\end{array}$ & 0.83 \\
\hline $\mathrm{TZ}$ in $\mathrm{mm}+$ & $30.75 \pm 9.55$ & $25.23 \pm 12.07$ & 0.22 \\
\hline Positive margins ^ & $3(25.00)$ & $3(23.08)$ & 0.90 \\
\hline Parametrial involvement ^ & $4(33.33)$ & $1(7.69)$ & 0.16 \\
\hline Lymph nodes count ^ & $20(17.5-29)$ & $19(12-28)$ & 0.46 \\
\hline
\end{tabular}

Abbreviations: BMI: body mass index; EBR: external beam radiotherapy; BT: brachytherapy; CT/EBRT concurrent chemotherapy and external beam radiotherapy; SCC: squamous cell carcinoma; ASCC: adenosquamous cell carcinoma; LVSI: lymphovascular space invasion; TZ: tumor size; + mean \pm standard deviation; ${ }^{\wedge}$ absolute value $(\%) ;{ }^{*}$ median (interquartile range).

\subsection{Identification of miRNA Target Genes and Signaling Pathways}

To identify gene targets and signaling pathways associated with the LNM+ status, we selected the seven miRNAs that were validated by RT-qPCR and showed clinical significance.

After bioinformatic analysis using miRWalk 3.0, we found 468 target genes (putative and validated) for this 7-miRNA molecular signature. Next, we performed KEGG and GO functional enrichment analyses using DAVID 6.8. The biological process terms were markedly enriched for regulation of transcription, regulation of cell migration, protein ubiquitination, epithelial cell-cell adhesion, and regulation of NF-kappa B transcription (Table 2). For the GO cellular component terms, the target genes were concentrated in the nucleus, cytosol, extracellular exosome, membrane, and rough endoplasmic reticulum, among others. The molecular function terms were enriched for protein binding, transcription factor binding, and beta-catenin binding. The KEGG pathways were predominantly enriched for cancer pathways, viral carcinogenesis, and the MAPK, ErbB, and GnRH signaling pathways (Supplementary File S1). In addition, interaction networks between target 
genes and the 7-miRNA signature were visualized with Cytoscape and CyTargetLinker (Figure 3 and Supplementary File S1) [33,35].

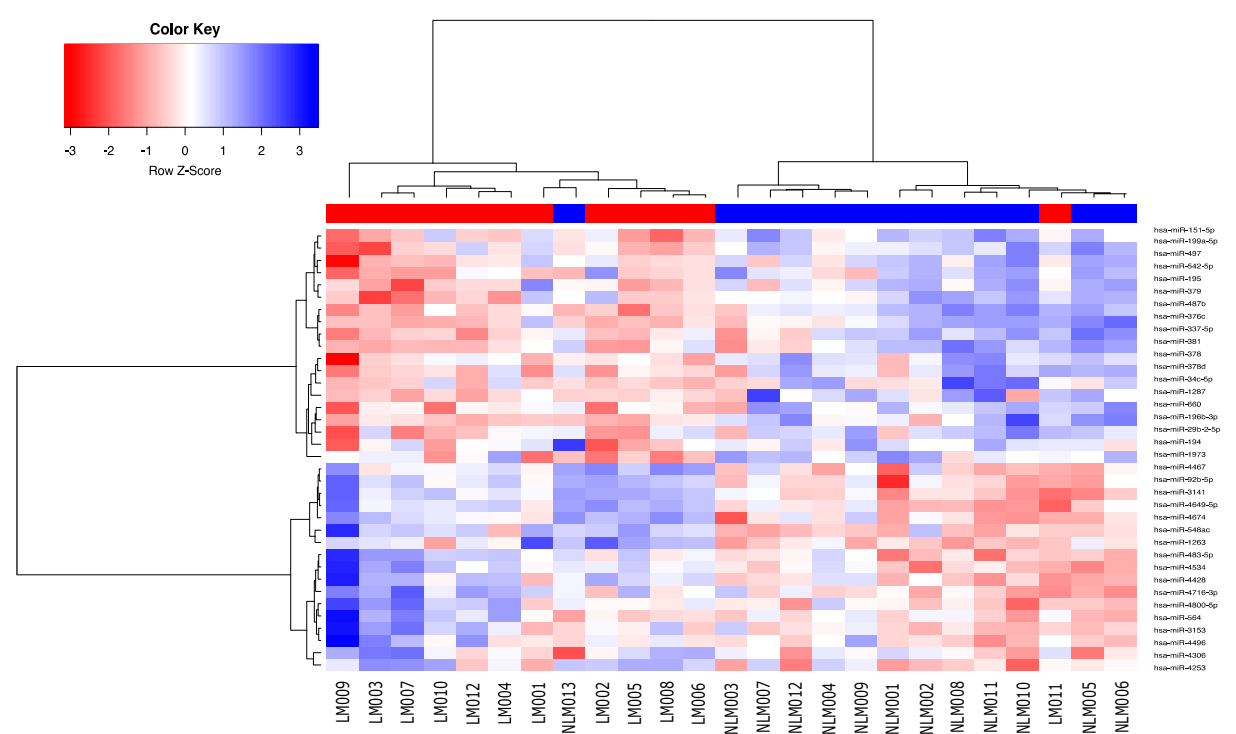

Figure 1. Heatmap of the supervised hierarchical clustering analysis of the 36 miRNAs expressed in the lymph node-positive group and the control group. The 12 samples in red exhibited lymph node metastasis (LNM), and the 13 samples in blue did not exhibit LNM.
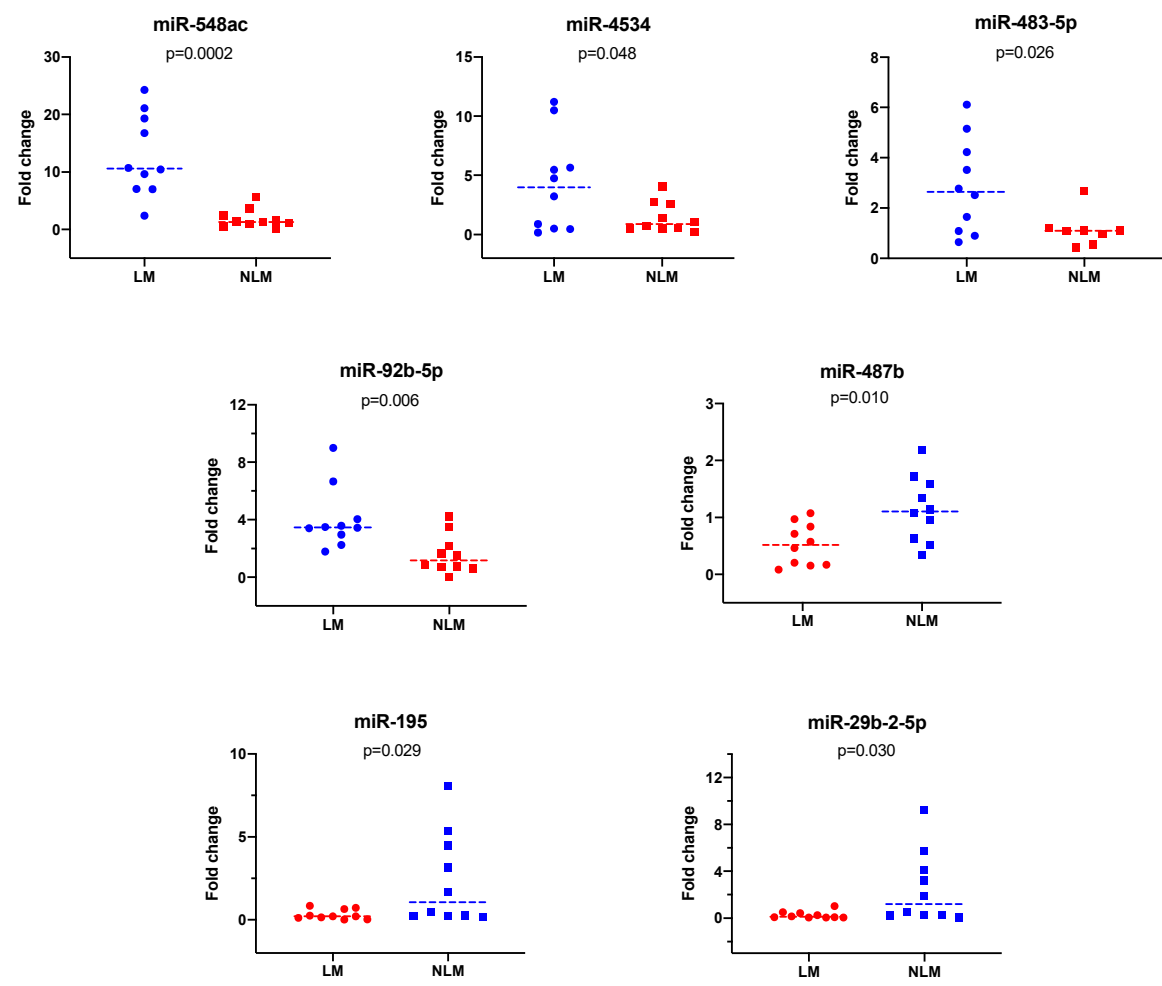

Figure 2. The seven miRNAs validated by RT-qPCR experiments. We were able to validate the expression of 7 of the 10 selected miRNAs by RT-qPCR experiments. miR-548ac, miR-4534, miR483-5p, and miR-92b-5p were overexpressed, whereas miR-487b, miR-195, and miR-29b-2-5p were underexpressed. LNM+: patients with lymph node metastasis, LNM-: patients without lymph node metastasis. miRNAs underexpressed in the microarray that were subjected to validation. The miRNAs miR-487b, miR-29b, and miR-195 were validated by RT-qPCR. LM: patients with lymph node metastasis, NLM: patients without lymph node metastasis. 


\subsection{Clinical Significance of the Identified miRNAs}

We calculated the estimated ORs in the LNM+ samples. Among the RT-qPCRvalidated miRNAs, statistically significant associations were found for the overexpressed miR-548ac (OR 3.29 95\% confidence interval (CI) 1.33-8.12, $p=0.010$ ), miR-4534 (OR 3.41 95\% CI 1.20-9.63, $p=0.021$ ), and miR-92b-5p (OR 3.44 95\% CI 1.10-10.80, $p=0.034$ ). In addition, statistically significant associations were identified for the underexpressed miRNAs, including miR-487b (OR 0.25 95\% CI 0.09-0.67, $p=0.005$ ), miR-195 (OR $0.1395 \%$ CI $0.03-0.59, p=0.008$ ), and miR-29b-2 (OR $0.3495 \%$ CI 0.14-0.82, $p=0.016$ ) (Table 3).

Table 2. Biological processes enriched in target genes.

\begin{tabular}{|c|c|c|c|}
\hline GO Term & Count & $p$ Value & Genes \\
\hline $\begin{array}{c}\text { Transcription from RNA polymerase II } \\
\text { promoter }\end{array}$ & 19 & $9.3 \times 10^{-5}$ & $\begin{array}{l}\text { DDX21, FOSL1, GABPA, IKZF3, MAFK, MNT, MLLT1, } \\
\text { PLAGL2, CLOCK, CCNT1, CCNT2, FOXC1, FOXJ2, } \\
\text { GTF2H5, HIVEP3, MBD1, NFIC, NFIX, SRF. }\end{array}$ \\
\hline $\begin{array}{l}\text { Regulation of transcription, } \\
\text { DNA-templated }\end{array}$ & 35 & $6.1 \times 10^{-4}$ & $\begin{array}{l}\text { KANK1, LRRFIP2, MACC1, MLLT1, MLLT6, POM121C, } \\
\text { SMAD3, THAP1, TMEM189-UBE2V1, BZW1, CALR, } \\
\text { CLOCK, CPNE1, FOXC1, GTF2H5, KAT6A, KDM2A, MKX, } \\
\text { PTPN14, RNF20, SRSF10, TCF3, UBE2V1, VHL, ZBTB10, } \\
\text { ZBTB34, ZBTB8A, ZNF276, ZNF391, ZNF426, ZNF429, } \\
\text { ZNF585B, ZNF662, ZNF747, ZNF813. }\end{array}$ \\
\hline Negative regulation of cell migration & 7 & $1.3 \times 10^{-3}$ & BCL2, KANK1, ARHGDIA, SRGAP1, RNF20, SRF, VCL. \\
\hline Protein ubiquitination & 13 & $2.1 \times 10^{-3}$ & $\begin{array}{l}\text { DCAF17, CDC42, CUL3, CAND1, MIB1, PARK2, RNF138, } \\
\text { RNF168, SOCS5, SOCS7, UBE2Q1, VHL, ZYG11B. }\end{array}$ \\
\hline $\begin{array}{l}\text { Positive regulation of transcription } \\
\text { from RNA polymerase II promoter }\end{array}$ & 24 & $3.1 \times 10^{-3}$ & $\begin{array}{l}\text { FOSL1, GABPA, IKZF3, MAFK, PAGR1, PLAGL2, SMAD3, } \\
\text { APP, CLOCK, CCNT1, CCNT2, FGF2, FOXC1, FOXJ2, } \\
\text { MAVS, MAPK3, NFIC, NFIX, PARK2, RPRD1B, SRF, TCF3, } \\
\text { TBL1XR1, TGFB1. }\end{array}$ \\
\hline $\begin{array}{l}\text { Nucleotide-binding oligomerization } \\
\text { domain-containing signaling pathway }\end{array}$ & 4 & $3.7 \times 10^{-3}$ & CYLD, TAB3, TMEM189-UBE2V1, UBE2V1 \\
\hline Epithelial cell-cell adhesion & 3 & $5.4 \times 10^{-3}$ & CDC42, SRF, VCL. \\
\hline $\begin{array}{l}\text { Positive regulation of transcription, } \\
\text { DNA-templated }\end{array}$ & 15 & $5.9 \times 10^{-3}$ & $\begin{array}{l}\text { SMAD3, TMEM189-UBE2V1, CLOCK, FGF2, FOXC1, FOXJ2, } \\
\text { HIVEP3, KAT6A, MAPK3, RNF20, TCF3, TBL1XR1, TGFB1, } \\
\text { UBE2V1, VHL. }\end{array}$ \\
\hline $\begin{array}{l}\text { Positive regulation of NF-kappa B } \\
\text { transcription factor activity }\end{array}$ & 8 & $7.6 \times 10^{-3}$ & $\begin{array}{l}\text { KRAS, TAB3, TMEM189-UBE2V1, CAMK2A, CLOCK, } \\
\text { TGFB1, UBE2V1. }\end{array}$ \\
\hline Transcription, DNA-templated & 38 & $9.3 \times 10^{-5}$ & $\begin{array}{l}\text { HIC2, KANK1, MACC1, MAFK, NAB2, PAGR1, POLR3A, } \\
\text { SMYD1, SMAD3, THAP1, BZW1, CLOCK, CPNE1, CCNT, } \\
\text { CCNT2, KAT6A, KDM2A, MAPK3, NFIC, NFIX, PARK2, } \\
\text { PTPN14, PTMA, PURB, TXNIP, TCF3, TBL1XR1, TLE4, } \\
\text { ZBTB10, ZBTB34, ZBTB8A, ZNF276, ZNF391, ZNF426, } \\
\text { ZNF429, ZNF585B, ZNF662, ZNF813. }\end{array}$ \\
\hline Protein polyubiquitination & 8 & $8.9 \times 10^{-3}$ & $\begin{array}{l}\text { BCL2, TMEM189-UBE2V1, CUL3, KLHL42, PARK2, } \\
\text { RNF138, RNF20, UBE2V1 }\end{array}$ \\
\hline
\end{tabular}

Table 3. Bivariate analysis of miRNAs associated with lymph node involvement in patients with early-stage cervical cancer treated with radical hysterectomy and bilateral pelvic lymphadenectomy.

\begin{tabular}{|c|c|c|c|c|}
\hline microRNA & $\begin{array}{l}\text { With Lymph Node } \\
\text { Involvement } \\
12(48 \%)\end{array}$ & $\begin{array}{l}\text { Without Lymph Node } \\
\text { Involvement } \\
13(52 \%)\end{array}$ & OR $(95 \% \mathrm{CI})$ & $p$ \\
\hline \multicolumn{5}{|c|}{ Overexpressed miRNAs } \\
\hline miR-548ac & $5.1(4.8-5.5)^{\dagger}$ & $3.5(3.1-3.9)^{+}$ & $3.29(1.33-8.12)$ & 0.010 \\
\hline miR-4534 & $5.0(4.6-4.61)^{\dagger}$ & $4.1(3.4-4.6)^{\dagger}$ & $3.41(1.20-9.63)$ & 0.021 \\
\hline $\operatorname{miR}-483-5 p$ & $5.5(4.6-5.8)^{+}$ & $4.4(4.1-5.1)^{+}$ & $2.40(0.98-5.83)$ & 0.053 \\
\hline miR-92b-5p & $6.9(6.5-7.2)^{+}$ & $5.9(5.5-6.6)^{\dagger}$ & $3.44(1.10-10.80)$ & 0.034 \\
\hline \multicolumn{5}{|c|}{ Underexpressed miRNAs } \\
\hline $\mathrm{miR}-487 \mathrm{~b}$ & $4.0(3.5-4.6)^{\dagger}$ & $5.8(5.3-6.4)^{\dagger}$ & $0.25(0.09-0.67)$ & 0.005 \\
\hline miR-195 & $9.8(9.3-10.0)^{\dagger}$ & $10.8(10.2-11.2)^{\dagger}$ & $0.13(0.03-0.59)$ & 0.008 \\
\hline $\operatorname{miR}-29 b-2-5 p$ & $3.9(2.8-4.9)^{\dagger}$ & $5.1(4.6-5.6)^{\dagger}$ & $0.34(0.14-0.82)$ & 0.016 \\
\hline
\end{tabular}




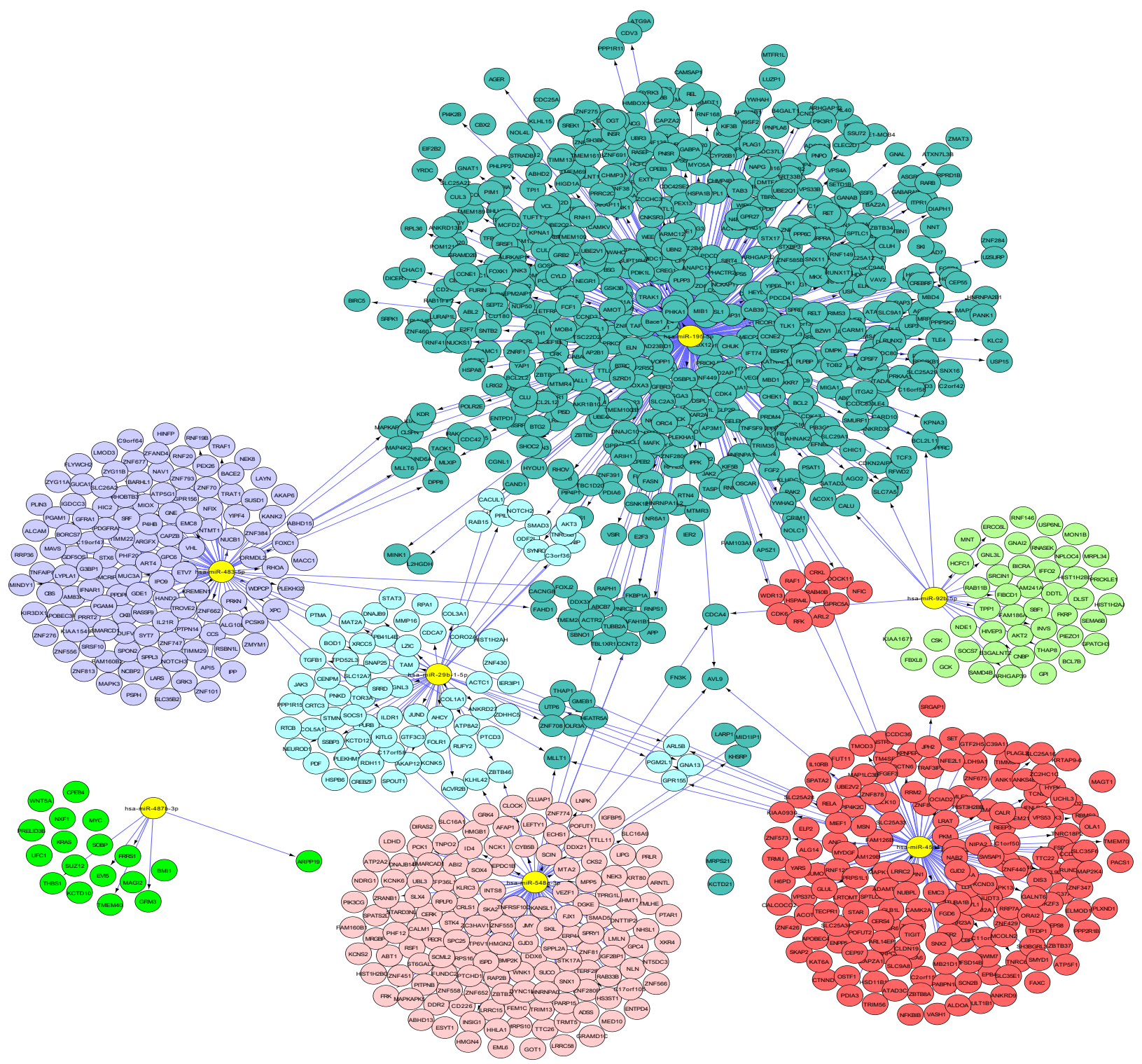

Figure 3. Interaction networks between target genes and the seven-miRNA signature. Target genes and the seven-miRNA signature were visualized with Cytoscape and CyTargetLinker. miRNAs are marked in yellow, while target genes are color-coded according to their regulatory miRNAs.

\section{Discussion}

The analysis of global miRNA expression revealed a profile of 36 differentially expressed miRNAs in the two sample groups. Of note, this miRNA profile was able to correctly classify $91.6 \%$ of the LNM+ samples. We found statistically significant differences in the expression (over- or underexpression) of the seven miRNAs between patients with early-stage CC with or without LNM.

In 2018, Chen Q et al. analyzed the differential expression of 422 miRNAs in 145 patients diagnosed with early-stage CC (including $32 \mathrm{LNM}+$ patients and $113 \mathrm{LNM}$ - patients) in The Cancer Genome Atlas (TCGA) database. They found that 75 miRNAs were differentially expressed between the 2 sample groups [36]. Interestingly, our results are consistent for five miRNAs (miR-548, miR-379, miR-337, miR-487b, and miR-376c) and several gene targets associated with lymph node involvement. The identification of the miRNA profile associated with the LNM+ status in patients with early-stage CC represents a diagnostic tool with relevant clinical application because it allows not only a better understanding of 
the biology of this disease but also the timely identification of patients who will require more aggressive treatment, closer monitoring, and possible detection of early relapse.

Among the miRNAs identified, miR-195 had an OR of $0.13(p=0.008)$ and was underexpressed in LNM+ patients. Overexpression of miR-195 is associated with cell migration, proliferation, and invasion in CC [37]. DU et al. found that miR-195 is involved in the cell cycle in the G1 to S transition, downregulating the expression of CCND2 and inhibiting cell proliferation; likewise, miR-195 decreases the expression of the transcription factor MYB, which is related to cell migration and invasion [37]. Li et al. showed that miRNA-195 is underexpressed in HeLa and SiHa CC cell lines $(p<0.0001)$ and is involved in the D1 signaling pathway; miRNA-195 underexpression also promotes cell proliferation and invasion [38]. These data corroborate those of the present study, according to which miR-195 underexpression was found in occult LNM+ patients. Likewise, Zhou et al. found that miR-195 was associated with LNM+ status $(p=0.009)$, an advanced clinical stage $(p=0.011)$, and greater cervical stroma involvement $(p=0.03)$ in patients with CC due to an association with Smad3 protein regulation, which is related to the migration and proliferation of malignant cells in CC as well as in other cancers such as esophageal and prostate cancer [39]. The underexpression of miR-487b was also strongly associated (OR $0.25, p=0.005$ ) with the LNM+ status in this study. Underexpression of miR-487b has been shown to be related to CC in some studies; however, the literature on this subject is limited, although studies have detected a relationship with the progression of tumors of the digestive tract and brain and of adenocarcinomas of the prostate and lung [40-43]. In a study by Hata et al., miRNA-487b was described as a negative regulator of metastasis by regulating the KRAS gene in colorectal cancer [44]. miR-29b-2-5p was found to be underexpressed in LNM+ patients (OR 0.34, $p=0.016$ ). Kinoshita et al. described that the miR-29 family of miRNAs, including miR-29a, miR-29b, and miR-29c, was significantly underexpressed in tumor tissues compared to nontumorous tissues [45]. A meta-analysis by Qi et al. indicated that underexpression of the miRNA-29 family is associated with OS (hazard ratio (HR) 1.57 95\% CI 1.18-2.08) and the disease-free period (HR 1.51, 95\% CI 0.99-2.30) [46]. Additionally, the miRNA-29b family has been associated with the induction of apoptosis through the Mcl-1, Bcl-2, AKT-2, and p53 signaling pathways as well as with the inhibition of metastasis by the Mcl-1, MMP-2, SOCs-2, and GATA-3 pathways, among others [47]. Regarding its relationship with CC, miR-29b underexpression was directly associated with the expression of the E6 and E7 proteins in human papillomavirus (HPV)infected patients, resulting in a modification of the cell cycle via the CDK6 pathway, which triggers malignant epithelial cells [48].

Regarding the overexpressed miRNAs, miR-483-5p was overexpressed in LNM+ patients (OR 2.40, $p=0.053$ ). Nagamitsu et al. found that miRNA 483-5p was overexpressed in patients with CC compared to those without CC, with FC $>3.0(p=0.01)$ [49]. In the present study, miR-483-5p was overexpressed by 2.21-fold $(p=0.001)$ in metastatic lymph nodes. Likewise, Nishi also found that serum miR-483-5p was significantly overexpressed in 40 patients with CC compared to 20 controls [50]. miR-4534 overexpression was strongly associated with LNM in patients with CC (OR 3.41, $p=0.021)$. No studies on the relationship between this miRNA and CC have been published; however, a relationship with prostate cancer was found. A study by Nip et al. reported that miRNA-4534 was overexpressed in a group of patients with prostate cancer. Likewise, the expression of this miRNA exerts an oncogenic effect by downregulating the PTEN suppressor gene. PTEN is a critical tumor suppressor gene related to survival, proliferation, cell migration, and angiogenesis through the PI3/Akt pathway [51]. Finally, another overexpressed miRNA associated with LNM+ status was miR-548ac, which was overexpressed in LNM+ patients (OR 3.29, $p=0.010$ ).

The strengths of this study are that our findings were validated by RT-qPCR and were based on optimal results. A weakness of this study is that it was performed on a small number of samples; thus, further validation is required. Some of the miRNAs found in our study are associated with the development, proliferation, and migration of malignant cells in CC as well as other malignant cancers. Prospective studies with a greater number of 
individuals are essential to evaluate this profile as a possible biomarker related to earlystage occult LNM. The results could help identify individuals at high risk of nodal disease who are candidates for chemotherapy (CT)/radiotherapy (RT) instead of surgery, which carries a high risk of being incomplete because of nodal disease.

\section{Conclusions}

A seven-miRNA signature associated with LNM+ status was determined in patients with early-stage CC who were treated with RH and BPL. This signature exhibited prognostic value for identifying early-stage CC patients with LNM+ status. These findings may help detect lymph node micrometastases that cannot be observed in imaging studies.

Supplementary Materials: The following materials are available online at https:/ /www.mdpi.com/ article/10.3390/curroncol29010023/s1. Supplementary File S1: Microarray data: contains the expression matrix of the normalized microarray data. DE miRNAs: contains the expression values of diferentially expressed miRNAs. qPCR Data: contains the raw data from the qPCR experiments and the calculations made to determine the fold change values. Target predicted: contains the list of predicted molecular targets for each miRNA. Keeg Pathways: contains the list of all keg pathways identified. Interaction networks: contains the data obtained for the construction of the interaction networks between the validated 7-miRNAs.

Author Contributions: Conceptualization, S.A.B.-M., A.P.-T., L.A.H.-M. and D.C.-d.L.; methodology, S.A.B.-M., C.P.-P., L.G.-A., D.P.-M. and D.C.-d.L.; software, A.P.-T., C.P.-P., S.M. and L.A.H.-M.; validation, S.A.B.-M., A.P.-T., S.M. and D.C.-d.L.; formal analysis, S.A.B.-M. and A.P.-T.; investigation, S.A.B.-M., C.P.-P., L.G.-A. and D.P.-M.; resources, L.A.H.-M. and D.C.-d.L.; data curation, S.M., L.G.-A. and D.P.-M.; writing-original draft preparation, S.A.B.-M., A.P.-T., S.M. and D.C.-d.L.; writingreview and editing, all authors; visualization, S.A.B.-M., A.P.-T. and L.G.-A.; supervision, C.P.-P., L.A.H.-M. and D.C.-d.L.; project administration, C.P.-P., L.A.H.-M. and D.C.-d.L. All authors have read and agreed to the published version of the manuscript.

Funding: This research received no external funding.

Institutional Review Board Statement: The study was conducted according to the guidelines of the Declaration of Helsinki and approved by the Institutional Review Board by the local institutional review boards (Comité de Investigación del Instituto Nacional de Cancerología), with approval reference (INCAN/CI/248/15).

Informed Consent Statement: Not applicable.

Data Availability Statement: Data can be made available by direct request to the corresponding author.

Acknowledgments: We would like to thank the National Cancer Institute for supporting this type of research project.

Conflicts of Interest: The authors declare no conflict of interest.

\section{References}

1. Ferlay, J.; Colombet, M.; Soerjomataram, I.; Mathers, C.; Parkin, D.M.; Piñeros, M.; Znaor, A.; Bray, F. Estimating the global cancer incidence and mortality in 2018: GLOBOCAN sources and methods. Int. J. Cancer 2019, 144, 1941-1953. [CrossRef]

2. Koh, W.-J.; Greer, B.E.; Abu-Rustum, N.R.; Apte, S.M.; Campos, S.M.; Chan, J.; Cho, K.; Cohn, D.; Crispens, M.A.; Dupont, N.; et al. Cervical Cancer. J. Natl. Compr. Cancer Netw. 2013, 11, 320-343. [CrossRef] [PubMed]

3. Delgado, G.; Bundy, B.; Zaino, R.; Sevin, B.-U.; Creasman, W.T.; Major, F. Prospective surgical-pathological study of disease-free interval in patients with stage IB squamous cell carcinoma of the cervix: A Gynecologic Oncology Group study. Gynecol. Oncol. 1990, 38, 352-357. [CrossRef]

4. Suprasert, P.; Charoenkwan, K.; Khunamornpong, S. Pelvic node removal and disease-free survival in cervical cancer patients treated with radical hysterectomy and pelvic lymphadenectomy. Int. J. Gynecol. Obstet. 2011, 116, 43-46. [CrossRef] [PubMed]

5. Togami, S.; Kamio, M.; Yanazume, S.; Yoshinaga, M.; Douchi, T. Can Pelvic Lymphadenectomy be omited in Stage IA2 to IIB Uterine Cervical Cancer? Int. J. Gynecol. Cancer 2014, 24, 1072-1076. [CrossRef]

6. Tanaka, Y.; Sawada, S.; Murata, T. Relationship between Lymph Node Metastases and Prognosis in Patients Irradiated Postoperatively for Carcinoma of the Uterine Cervix. Acta Radiol. Oncol. 1984, 23, 455-459. [CrossRef] [PubMed]

7. Luo, L.; Luo, Q.; Tang, L. Diagnostic value and clinical significance of MRI and CT in detecting lymph node metastasis of early cervical cancer. Oncol. Lett. 2019, 19, 700-706. [CrossRef] 
8. Reinhardt, M.J.; Ehritt-Braun, C.; Vogelgesang, D.; Ihling, C.; Högerle, S.; Mix, M.; Moser, E.; Krause, T.M. Metastatic Lymph Nodes in Patients with Cervical Cancer: Detection with MR Imaging and FDG PET. Radiology 2001, 218, 776-782. [CrossRef]

9. Lin, A.J.; Wright, J.D.; Dehdashti, F.; Siegel, B.A.; Markovina, S.; Schwarz, J.; Thaker, P.H.; Mutch, D.G.; Powell, M.A.; Grigsby, P.W. Impact of tumor histology on detection of pelvic and para-aortic nodal metastasis with 18F-fluorodeoxyglucose-positron emission tomography in stage IB cervical cancer. Int. J. Gynecol. Cancer 2019, 29, 1351-1354. [CrossRef] [PubMed]

10. Bhatla, N.; Aoki, D.; Sharma, D.N.; Sankaranarayanan, R. Cancer of the cervix uteri. Int. J. Gynecol. Obstet. 2018, 143, 22-36. [CrossRef]

11. Bartel, D.P. MicroRNAs: Genomics, Biogenesis, Mechanism, and Function. Cell 2004, 116, 281-297. [CrossRef]

12. Pedroza-Torres, A.; López-Urrutia, E.; Garcia, V.; Jacobo-Herrera, N.; Herrera, L.A.; Peralta-Zaragoza, O.; López-Camarillo, C.; De Leon, D.C.; Fernández-Retana, J.; Cerna-Cortés, J.F.; et al. MicroRNAs in Cervical Cancer: Evidences for a miRNA Profile Deregulated by HPV and Its Impact on Radio-Resistance. Molecules 2014, 19, 6263-6281. [CrossRef] [PubMed]

13. Lee, J.-W.; Choi, C.H.; Choi, J.-J.; Park, Y.-A.; Kim, S.-J.; Hwang, S.Y.; Kim, W.Y.; Kim, T.-J.; Lee, J.-H.; Kim, B.-G.; et al. Altered MicroRNA Expression in Cervical Carcinomas. Clin. Cancer Res. 2008, 14, 2535-2542. [CrossRef] [PubMed]

14. Calin, G.; Croce, C.M. MicroRNA Signatures in Human Cancers. Nat. Rev. Cancer 2006, 6, 857-866. [CrossRef] [PubMed]

15. Bonci, D.; Coppola, V.; Musumeci, M.; Addario, A.; Giuffrida, R.; Memeo, L.; D’Urso, L.; Pagliuca, A.; Biffoni, M.; Labbaye, C.; et al. The miR-15a-miR-16-1 cluster controls prostate cancer by targeting multiple oncogenic activities. Nat. Med. 2008, 14, 1271-1277. [CrossRef] [PubMed]

16. Calin, G.A.; Dumitru, C.D.; Shimizu, M.; Bichi, R.; Zupo, S.; Noch, E.; Aldler, H.; Rattan, S.; Keating, M.; Rai, K.; et al. Nonlinear partial differential equations and applications: Frequent deletions and down-regulation of micro- RNA genes miR15 and miR16 at 13q14 in chronic lymphocytic leukemia. Proc. Natl. Acad. Sci. USA 2002, 99, 15524-15529. [CrossRef] [PubMed]

17. Miao, J.; Regenstein, J.M.; Xu, D.; Zhou, D.; Li, H.; Zhang, H.; Li, C.; Qiu, J.; Chen, X. The roles of microRNA in human cervical cancer. Arch. Biochem. Biophys. 2020, 690, 108480. [CrossRef] [PubMed]

18. Ribeiro, J.; Sousa, H. MicroRNAs as biomarkers of cervical cancer development: A literature review on miR-125b and miR-34a. Mol. Biol. Rep. 2014, 41, 1525-1531. [CrossRef]

19. Qin, W.; Dong, P.; Ma, C.; Mitchelson, K.; Deng, T.; Zhang, L.; Sun, Y.; Feng, X.; Ding, Y.; Lu, X.; et al. MicroRNA-133b is a key promoter of cervical carcinoma development through the activation of the ERK and AKT1 pathways. Oncogene 2011, 31, 4067-4075. [CrossRef]

20. Park, S.; Kim, J.; Eom, K.; Oh, S.; Kim, S.; Kim, G.; Ahn, S.; Park, K.H.; Chung, D.; Lee, H. microRNA-944 overexpression is a biomarker for poor prognosis of advanced cervical cancer. BMC Cancer 2019, 19, 1-8. [CrossRef]

21. Yang, D.; Zhang, Q. miR-152 may function as an early diagnostic and prognostic biomarker in patients with cervical intraepithelial neoplasia and patients with cervical cancer. Oncol. Lett. 2019, 17, 5693-5698. [CrossRef] [PubMed]

22. Lui, W.-O.; Pourmand, N.; Patterson, B.K.; Fire, A. Patterns of Known and Novel Small RNAs in Human Cervical Cancer. Cancer Res. 2007, 67, 6031-6043. [CrossRef]

23. Zhao, S.; Yao, D.-S.; Chen, J.-Y.; Ding, N. Aberrant Expression of miR-20a and miR-203 in Cervical Cancer. Asian Pac. J. Cancer Prev. 2013, 14, 2289-2293. [CrossRef]

24. Chen, J.; Yao, D.; Li, Y.; Chen, H.; He, C.; Ding, N.; Lu, Y.; Ou, T.; Zhao, S.; Li, L.; et al. Serum microRNA expression levels can predict lymph node metastasis in patients with early-stage cervical squamous cell carcinoma. Int. J. Mol. Med. 2013, 32, 557-567. [CrossRef] [PubMed]

25. Shen, S.-N.; Wang, L.-F.; Jia, Y.-F.; Hao, Y.-Q.; Zhang, L.; Wang, H. Upregulation of microRNA-224 is associated with aggressive progression and poor prognosis in human cervical cancer. Diagn. Pathol. 2013, 8, 69. [CrossRef] [PubMed]

26. Murtagh, F.; Legendre, P. Ward's Hierarchical Agglomerative Clustering Method: Which Algorithms Implement Ward's Criterion? J. Classif. 2014, 31, 274-295. [CrossRef]

27. Livak, K.J.; Schmittgen, T.D. Analysis of relative gene expression data using real-time quantitative PCR and the $2^{-\Delta \Delta C_{\mathrm{T}}}$ method. Methods 2001, 25, 402-408. [CrossRef]

28. Dweep, H.; Sticht, C.; Pandey, P.; Gretz, N. miRWalk-Database: Prediction of possible miRNA binding sites by "walking" the genes of three genomes. J. Biomed. Inform. 2011, 44, 839-847. [CrossRef]

29. Huang, D.W.; Sherman, B.T.; Lempicki, R.A. Systematic and integrative analysis of large gene lists using DAVID bioinformatics resources. Nat. Protoc. 2009, 4, 44-57. [CrossRef]

30. Ding, J.; Li, X.; Hu, H. TarPmiR: A new approach for microRNA target site prediction. Bioinformatics 2016, 32, $2768-2775$. [CrossRef]

31. Kanehisa, M.; Sato, Y.; Furumichi, M.; Morishima, K.; Tanabe, M. New approach for understanding genome variations in KEGG. Nucleic Acids Res. 2018, 47, D590-D595. [CrossRef]

32. Ogata, H.; Goto, S.; Sato, K.; Fujibuchi, W.; Bono, H.; Kanehisa, M. KEGG: Kyoto Encyclopedia of Genes and Genomes. Nucleic Acids Res. 1999, 27, 29-34. [CrossRef] [PubMed]

33. Shannon, P.; Markiel, A.; Ozier, O.; Baliga, N.S.; Wang, J.T.; Ramage, D.; Amin, N.; Schwikowski, B.; Ideker, T. Cytoscape: A Software Environment for Integrated Models of Biomolecular Interaction Networks. Genome Res. 2003, 13, 2498-2504. [CrossRef]

34. Kutmon, M.; Kelder, T.; Mandaviya, P.; Evelo, C.; Coort, S. CyTargetLinker: A Cytoscape App to Integrate Regulatory Interactions in Network Analysis. PLoS ONE 2013, 8, e82160. [CrossRef] [PubMed] 
35. Kutmon, M.; Ehrhart, F.; Willighagen, E.L.; Evelo, C.T.; Coort, S.L. CyTargetLinker app update: A flexible solution for network extension in Cytoscape. F1000Research 2019, 7, 743. [CrossRef] [PubMed]

36. Chen, Q.; Zeng, X.; Huang, D.; Qiu, X. Identification of differentially expressed miRNAs in early-stage cervical cancer with lymph node metastasis across The Cancer Genome Atlas datasets. Cancer Manag. Res. 2018, 10, 6489-6504. [CrossRef] [PubMed]

37. Du, X.; Lin, L.; Zhang, L.; Jiang, J. microRNA-195 inhibits the proliferation, migration and invasion of cervical cancer cells via the inhibition of CCND2 and MYB expression. Oncol. Lett. 2015, 10, 2639-2643. [CrossRef]

38. Li, Z.; Wang, H.; Wang, Z.; Cai, H. MiR-195 inhibits the proliferation of human cervical cancer cells by directly targeting cyclin D1. Tumor Biol. 2015, 37, 6457-6463. [CrossRef] [PubMed]

39. Zhao, W.; Zou, J.; Wang, B.; Fan, P.; Mao, J.; Li, J.; Liu, H.; Xiao, J.; Ma, W.; Wang, M.; et al. microRNA-140 suppresses the migration and invasion of colorectal cancer cells through targeting Smad3. Zhonghua Zhong Liu Za Zhi Chin. J. Oncol. 2014, 36, 739-745.

40. Banno, K.; Iida, M.; Yanokura, M.; Kisu, I.; Iwata, T.; Tominaga, E.; Tanaka, K.; Aoki, D. MicroRNA in Cervical Cancer: OncomiRs and Tumor Suppressor miRs in Diagnosis and Treatment. Sci. World J. 2014, 2014, 1-8. [CrossRef]

41. Feng, N.; Wang, Z.; Zhang, Z.; He, X.; Wang, C.; Zhang, L. miR-487b promotes human umbilical vein endothelial cell proliferation, migration, invasion and tube formation through regulating THBS1. Neurosci. Lett. 2015, 591, 1-7. [CrossRef] [PubMed]

42. Formosa, A.; Markert, E.K.; Lena, A.M.; Italiano, D.; Agro, E.F.; Levine, A.J.; Bernardini, S.; Garabadgiu, A.V.; Melino, G.; Candi, E. MicroRNAs, miR-154, miR-299-5p, miR-376a, miR-376c, miR-377, miR-381, miR-487b, miR-485-3p, miR-495 and miR-654-3p, mapped to the $14 \mathrm{q} 32.31$ locus, regulate proliferation, apoptosis, migration and invasion in metastatic prostate cancer cells. Oncogene 2013, 33, 5173-5182. [CrossRef] [PubMed]

43. Gattolliat, C.-H.; Thomas, L.; Ciafre', S.A.; Meurice, G.; Le Teuff, G.; Job, B.; Richon, C.; Combaret, V.; Dessen, P.; Valteaucouanet, D.; et al. Expression of miR-487b and miR-410 encoded by $14 q 32.31$ locus is a prognostic marker in neuroblastoma. Br. J. Cancer 2011, 105, 1352-1361. [CrossRef]

44. Hata, T.; Mokutani, Y.; Takahashi, H.; Haraguchi, N.; Inoue, A.; Munakata, K.; Nagata, K.; Nishimura, J.; Hata, T.; Matsuda, C.; et al. Identification of microRNA- $487 \mathrm{~b}$ as a negative regulator of liver metastasis by regulation of KRAS in colorectal cancer. Int. J. Oncol. 2016, 50, 487-496. [CrossRef]

45. Kinoshita, T.; Nohata, N.; Hanazawa, T.; Kikkawa, N.; Yamamoto, N.; Yoshino, H.; Itesako, T.; Enokida, H.; Nakagawa, M.; Okamoto, Y.; et al. Tumour-suppressive microRNA-29s inhibit cancer cell migration and invasion by targeting laminin-integrin signalling in head and neck squamous cell carcinoma. Br. J. Cancer 2013, 109, 2636-2645. [CrossRef]

46. Qi, Y.; Huang, Y.; Pang, L.; Gu, W.; Wang, N.; Hu, J.; Cui, X.; Zhang, J.; Zhao, J.; Liu, C.; et al. Prognostic value of the MicroRNA-29 family in multiple human cancers: A meta-analysis and systematic review. Clin. Exp. Pharmacol. Physiol. 2017, 44, 441-454. [CrossRef]

47. Yang, J.-R.; Yan, B.; Guo, Q.; Fu, F.-J.; Wang, Z.; Yin, Z.; Wei, Y. The role of miR-29b in cancer: Regulation, function, and signaling. OncoTargets Ther. 2015, 8, 539-548. [CrossRef] [PubMed]

48. Li, Y.; Wang, F.; Xu, J.; Ye, F.; Shen, Y.; Zhou, J.; Lu, W.; Wan, X.; Ma, D.; Xie, X. Progressive miRNA expression profiles in cervical carcinogenesis and identification of HPV-related target genes for miR-29. J. Pathol. 2011, 224, 484-495. [CrossRef] [PubMed]

49. Nagamitsu, Y.; Nishi, H.; Sasaki, T.; Takaesu, Y.; Terauchi, F.; Isaka, K. Profiling analysis of circulating microRNA expression in cervical cancer. Mol. Clin. Oncol. 2016, 5, 189-194. [CrossRef]

50. Nishi, H.; Nagamitsu, Y.; Sasaki, T.; Takaesu, Y.; Terauchi, F.; Isaka, K. Exosomal-miRNA profiles as diagnostic biomarkers in cervical cancer. J. Clin. Oncol. 2012, 30, 10557. [CrossRef]

51. Nip, H.; Dar, A.A.; Saini, S.; Colden, M.; Varahram, S.; Chowdhary, H.; Yamamura, S.; Mitsui, Y.; Tanaka, Y.; Kato, T.; et al. Oncogenic microRNA-4534 regulates PTEN pathway in prostate cancer. Oncotarget 2016, 7, 68371-68384. [CrossRef] [PubMed] 